Check for updates

Cite this: RSC Adv., 2019, 9, 16328

Received 4th March 2019

Accepted 15th April 2019

DOI: 10.1039/c9ra01574d

rsc.li/rsc-advances

\title{
Enhanced luminescence and tunable magnetic properties of lanthanide coordination polymers based on fluorine substitution and phenanthroline ligand $\dagger$
}

\author{
Xun Feng, (D) *a Yapei Shang, ${ }^{\text {ac }}$ Heng Zhang, ${ }^{\text {ac }}$ Rongfang Li, ${ }^{a}$ Weizhou Wang, ${ }^{\text {a }}$ \\ Daoming Zhang, ${ }^{a}$ Liya Wang ${ }^{\star a b}$ and Zhongjun $\mathrm{Li}^{\mathrm{c}}$
}

\begin{abstract}
A family of highly stable lanthanide coordination polymers incorporating fluorine-substituted carboxylate tectonics and the rigid ligand phenanthroline, namely, $\left\{\left[\mathrm{Ln}_{m}(\mathrm{Tfbda})_{n}(\mathrm{Phen})_{2} \cdot 2 \mathrm{H}_{2} \mathrm{O}\right] \cdot 2 \mathrm{H}_{2} \mathrm{O}\right\}_{z \prime}(\operatorname{Ln}=\operatorname{Pr}(1)$, Ho (4) and Gd (7), $m=2, n=3) ;\left\{\left[\mathrm{Ln}_{3}(\mathrm{Tfbda})_{m_{1}}(\mathrm{Tfba})_{m_{2}}(\text { Phen) })_{n} \cdot 2 \mathrm{H}_{2} \mathrm{O}\right] \cdot \mathrm{H}_{2} \mathrm{O}\right\}_{z}(z>1, \operatorname{Ln}=\operatorname{Dy}(3), \operatorname{Er}(5)$ and $\left.\mathrm{Yb}(6), m_{1}=4, m_{2}=1, n=3\right)$; $\left[\mathrm{Ln}_{2}\left(\mathrm{H}_{2} \mathrm{Tfbda}\right)_{4}(\text { Phen })_{2} \cdot\left(\mathrm{H}_{2} \mathrm{O}\right)_{2}\right] \cdot$ Phen $(\mathrm{Ln}=\mathrm{Nd}(2))$, Tfbda $=3,4,5,6$ tetrafluoro-benzene-1,2-dioic acid, Tfba $=2,3,4,5$-tetrafluorobenzoic acid have been afforded under hydrothermal conditions. The series of coordination polymers exhibited diverse structural motifs, from dinuclear cluster to 1-D chain arrary, displaying efficiently sensitized luminescence over a spectral range from visible to near-infrared (NIR) region and a long lifetime, due to efficient energy transfer from fluorine-substituted ligands to Ln(III) centers in solid state. Slow relaxation magnetization and significant frequency- and temperature-dependent peaks were observed in trinuclear Dy(II)-based coordination polymer 3. DC magnetic susceptibility studies reveal the existence of weak ferromagnetic interaction within 7
\end{abstract}

\section{Introduction}

In recent decades, the lanthanide metal-organic frameworks (Ln-MOFs) based on multifunctional molecules have become one of the most intriguing issues in modern solid-state chemistry, attracting wide interest because of their unprecedented stability, large paramagnetism, large Stokes shift, long lifetime, and the electrostatic nature of their coordination chemistry. They have been regarded as a unique and emerging class of targeted functional materials that extends the possible combination of physical properties to electronic conductivity, magnetism and display devices. ${ }^{\mathbf{1 , 2}}$ Especially, there has been an escalating interest in the exploration of lanthanide nearinfrared (NIR) emission because of its promising applications

${ }^{a}$ College of Chemistry and Chemical Engineering, Henan Key Laboratory of Function Oriented Porous Materials, Luoyang Normal University, Luoyang 471934, China. E-mail:fengx@lynu.edu.cn

${ }^{b}$ School of Life Science and Technology, Nanyang Normal University, Nanyang, 473601, China. E-mail: wlya@lynu.edu.cn

${ }^{c}$ College of Chemistry and Molecular Engineering, Zhengzhou University, Zhengzhou, 450001, China

$\dagger$ Electronic supplementary information (ESI) available: The full experimental information of complexes, the simulated and experimental powder XRD patterns of 2-6, additional structural, UV-visible absorption and spectroscopy figures, and the tables of selected bond distances/angles, etc. CCDC 1895890-1895895. For ESI and crystallographic data in CIF or other electronic format see DOI: $10.1039 /$ c9ra01574d in optical devices, ${ }^{3}$ bioanalytical detection, ${ }^{4}$ optical amplification, and biological imaging, ${ }^{5}$ particularly, for the fabrication of materials that integrate or modify the intrinsic characteristics of Ln species. Various design strategies offer pathways to produce materials for specific applications, including the exploitation of the modular nature of Ln(III) MOFs or coordination polymers (CP). ${ }^{6}$ The use of multi-carboxylate-bridged metal clusters as metal-organic sub-building units (SBUs) to build extended self-assembled structures is relatively mature and has already been widely explored based on some benzoic/ pyridine multi-carboxylate coordination polymers. ${ }^{7,8}$ However, the systematic study of NIR luminescence (visible light excitation) and magnetism of heavy lanthanide has been less documented to date. Large-spin multiplicity of the spin ground state of $\operatorname{Ln}(\mathrm{III})$ ions ensure their compounds can be employed to build either single-molecule magnets (SMMs) for highly anisotropic Dy(III)-based systems, ${ }^{9}$ or low-temperature molecular magnetic coolers for isotropic $\mathrm{Gd}(\mathrm{III})$-contained compounds. ${ }^{\mathbf{1 0}}$ The magnetic properties of these lanthanides continue to be an attractive research field in high-density data storage technologies and molecular spintronics. However, the luminescence intensity is often quenched by the non-radiative exchange of electronic energy of $\mathrm{Ln}(\mathrm{III})$ to the high vibration modes of $\mathrm{O}-\mathrm{H}$ and $\mathrm{C}-\mathrm{H}$ bonding, ${ }^{11}$ which are detrimental to their application in displays, light signal transmission, and sensing devices. The search for a new class of magneto/luminescent compounds is 
a great challenge. The positions of Ln(III) ion must be conveniently shielded against the intervention of solvent molecules to inhibit nonradiative deactivation. ${ }^{12}$ Instead, sensitization of the metal emission is more effectively achieved through an organic ligand with strongly absorbing proximal chromospheres, taking advantage of the so-called "antennae" effect, ${ }^{13}$ in which the intensities of characteristic lanthanide emissions are significantly enhanced. Considering the low vibrational C-F frequency $\left(1220 \mathrm{~cm}^{-1}\right)$, fluorinated organic ligands can remarkably improve the luminescence intensity of compounds by reducing the fluorescence quenching effect of the vibrational $\mathrm{C}-\mathrm{H}$ bond (the energy level $\mathrm{C}-\mathrm{H}$ at $2950 \mathrm{~cm}^{-1}$ ). ${ }^{14}$ Therefore, as a fluorinated ligand, tetrafluoro-benzene-1,2-dioic acid ( $\left.\mathrm{H}_{2} \mathrm{Tfbda}\right)$ is a good candidate for constructing luminescent MOFs. ${ }^{8}$ Another beneficial effect of the fluorine-substituted ligand employed is the enhanced water solubility of an anion luminescent probe, which can be realized efficiently in solution. ${ }^{15}$ Neutral bidentate 1,10-phenanthroline (Phen) is a chromophoric ligand and versatile building block for constructing luminescent compounds, ${ }^{\mathbf{1 6}}$ because it not only can chelate to a $\operatorname{Ln}($ III) ion and protect the $\mathrm{Ln}(\mathrm{III})$ ion from bonding with water molecules, but also absorb and efficiently transfer energy to Ln(III) excited states via efficient energy transfer. Based on the considerations above and as continuation of our investigations, ${ }^{17}$ in this contribution, a family of new lanthanide coordination polymers containing fluorine-substituted carboxylate with rigid phenanthroline ligands have been isolated successfully to provide further understanding of the structure diversity and the effect of aromatic $\mathrm{C}-\mathrm{F}$ substitution of the ligand on the photophysical properties of a series of compounds. The thermal decomposition, fluorescence comparisons, and magnetic properties are also investigated.

\section{Experimental section}

\section{Materials and physical measurements}

(See ESI $\dagger$ ).

\section{Synthesis of polymer 1}

$\left\{\left[\mathrm{Pr}_{2}(\mathrm{Tfbda})_{3}(\mathrm{Phen})_{2} \cdot 2 \mathrm{H}_{2} \mathrm{O}\right] \cdot 2 \mathrm{H}_{2} \mathrm{O}\right\}_{z}(\mathbf{1}): \mathrm{H}_{2} \mathrm{Tfbda}$ acid $(0.0724 \mathrm{~g}$, $0.31 \mathrm{mmol})$ and Phen $(0.0381 \mathrm{~g}, 0.22 \mathrm{mmol})$ were mixed in a water/alcohol solution $(\mathrm{v} / \mathrm{v}=1.8,10 \mathrm{~mL})$ with an aqueous solution $(10 \mathrm{~mL})$ of $\operatorname{Pr}\left(\mathrm{CH}_{3} \mathrm{COO}\right)_{3} \cdot 6 \mathrm{H}_{2} \mathrm{O}(0.075 \mathrm{~g}, 0.2 \mathrm{mmol})$. After stirring for $20 \mathrm{~min}$, the $\mathrm{pH}$ value was adjusted to 5.0 by adding triethyleneamine, and the mixture was placed into a $25 \mathrm{~mL}$ Teflon-lined autoclave under autogenous pressure, heated at $140{ }^{\circ} \mathrm{C}$ for $80 \mathrm{~h}$. Then, the autoclave was cooled over a period of $30 \mathrm{~h}$ at a rate of $10{ }^{\circ} \mathrm{C} \mathrm{h}^{-1}$. After filtration, the green product was washed with distilled water and then vacuum dried. Pale green crystals of $\mathbf{1}[0.031 \mathrm{~g}, 34 \%$ based on $\operatorname{Pr}(\mathrm{III})]$ were obtained, which were suitable for X-ray diffraction analysis. Elemental analysis (\%) found: C, 40.42; H, 1.75; N, 3.96. Calc. for $\mathrm{C}_{48} \mathrm{H}_{24} \mathrm{~F}_{12} \mathrm{~N}_{4} \mathrm{O}_{16} \mathrm{Pr}_{2}$ : C, 40.53; $\mathrm{H}, 1.70 ; \mathrm{N}, 3.94 \%$. IR ( $\mathrm{KBr}$ pellet, $\mathrm{cm}^{-1}$ ): $3423 \mathrm{br}, 3167 \mathrm{~s}, 1628 \mathrm{vs}, 1414$ vs, $1192 \mathrm{~s}, 1091 \mathrm{~m}$, 918 s, 838 s, 770 s, 663 s, and 626 s.
The same procedure for coordination polymer 1 was employed to prepare the other compounds; see ESI $\dagger$ for details. In order to the evaluate the triplet excited state energy and study the magnetic properties of mid-lanthanide, an analogous compound, $\left\{\left[\mathrm{Gd}_{2}(\mathrm{Tfbda})_{2}(\mathrm{Phen})_{2} \cdot 2 \mathrm{H}_{2} \mathrm{O}\right] \cdot 2 \mathrm{H}_{2} \mathrm{O}\right\}_{z}$ (7) has also been afforded.

\section{Crystallographic data collection and refinement}

Single-crystal X-ray diffraction data for 1-6 were collected on an Oxford Diffraction Super Nova area detector diffractometer for data reduction and empirical absorption correction. The crystal structure was solved by direct methods, using SHELXS-2014 and least-squares refined with SHELXL-2014, ${ }^{\mathbf{1 8 , 1 9}}$ with anisotropic thermal displacement parameters. Disordered fluorine atoms were restrained in order to obtain reasonable thermal parameters. The details of the crystal parameters, data collection and refinements for coordination polymers are reported in Table 1; the crystal parameters of 7 are listed in Tables S1 and S2 in the ESI. $\dagger$

\section{Results and discussion}

\section{Infrared spectra}

In the IR spectra of compounds 1-6 (see Fig. S1, ESI $\dagger$ ), the broad strong absorption peaks in the frequency range of 3300$3500 \mathrm{~cm}^{-1}$ are assigned to $\mathrm{O}-\mathrm{H}$ stretching vibration from water molecules. The weak broad peaks at about $3000 \mathrm{~cm}^{-1}$ correspond to asymmetric stretching vibrations of $\mathrm{C}-\mathrm{H}$ from Phen blocks. The sharp bands in the ranges of 1600-1530 and 1450$1380 \mathrm{~cm}^{-1}$ are attributed to asymmetric and symmetric stretching vibrations of carboxylic groups, respectively, ${ }^{20}$ which also indicate the presence of both bridging and chelating coordination modes, based on the Deacon-Philips rule. ${ }^{21}$ The obvious absorption bands about $1300-1100 \mathrm{~cm}^{-1}$ are attributed to stretching vibration of the $\mathrm{C}-\mathrm{F}$ bond attached to the benzene ring.

\section{Description of the structures}

Single-crystal X-ray diffraction reveals that the series of coordination polymers exhibited diverse structural motifs, although all the compounds crystallize in the triclinic system, with a space group of $P_{21 / c} .1,4$ and 7 are isostructural, based on binuclear sub-building units; 3, 5 and $\mathbf{6}$ are isostructural, based on a trinuclear cluster; whereas 2 is a zero-dimensional compound (see ESI $\dagger$ ). The structural diversity is due to the discrepancy in lanthanide ions and the $\mathrm{pH}$ conditions during synthesis of the compounds. ${ }^{22}$ The structure of $\mathbf{1}$ and $\mathbf{3}$ are selected and described in detail herein. The asymmetric unit contains two $\operatorname{Pr}(\mathrm{III})$ ions, two Phen moieties, three Tfbda ligands and two coordination water molecules, as well as two lattice waters, as illustrated in Fig. 1(a). In this unit, the first $\operatorname{Pr}($ III) ion is nine-coordinated with an $\mathrm{O}_{8} \mathrm{~N}$ donor set, among which six $\mathrm{O}$ atoms are from Tfbda ligands, while another one $\mathrm{O}$ atom is from water molecule; two $\mathrm{N}$ atoms from Phen moiety completed the polyhedron geometry, which is best described as a distorted mono-capped anti-prism. The second $\operatorname{Pr}(\mathrm{III})$ ion adopts 


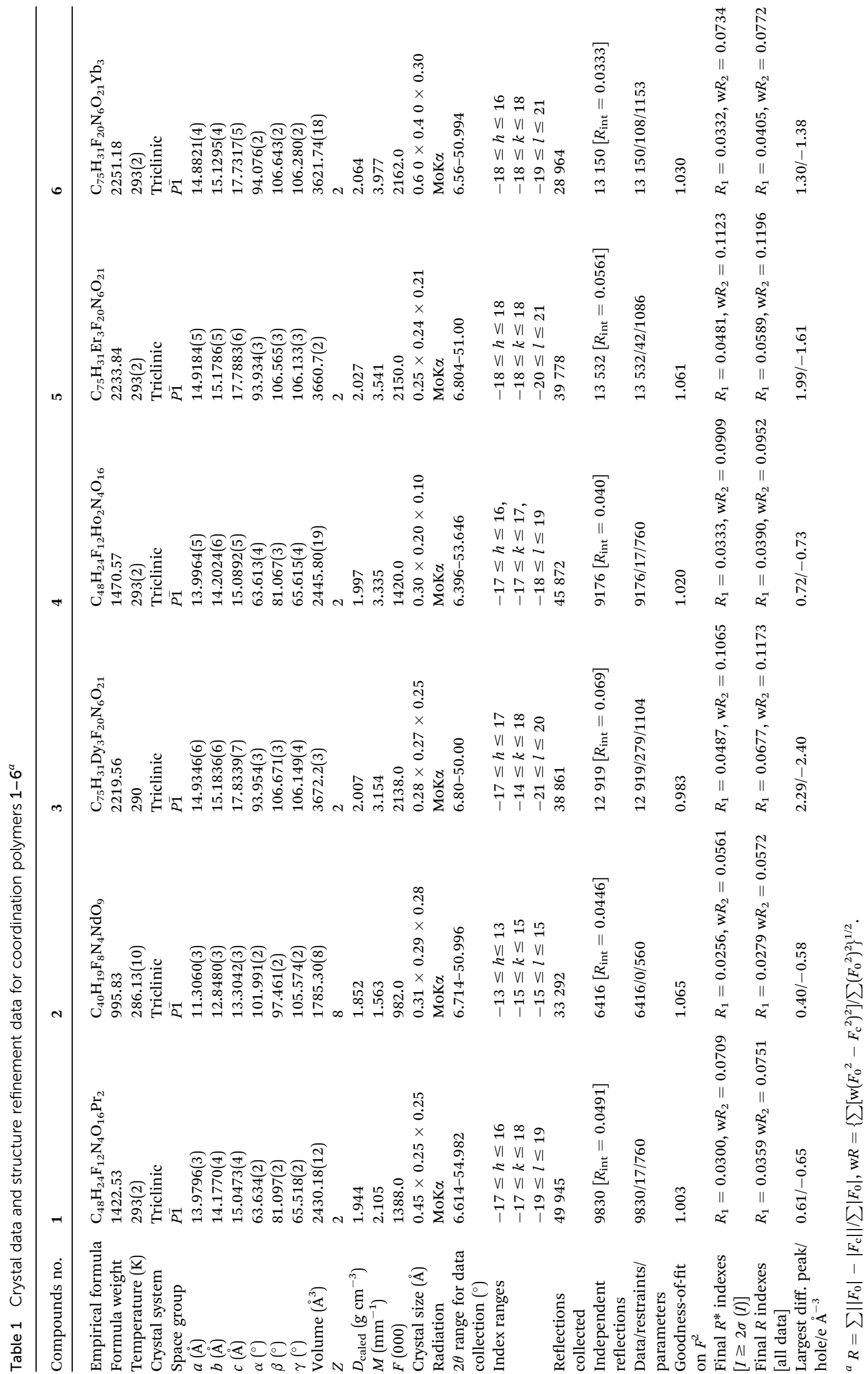




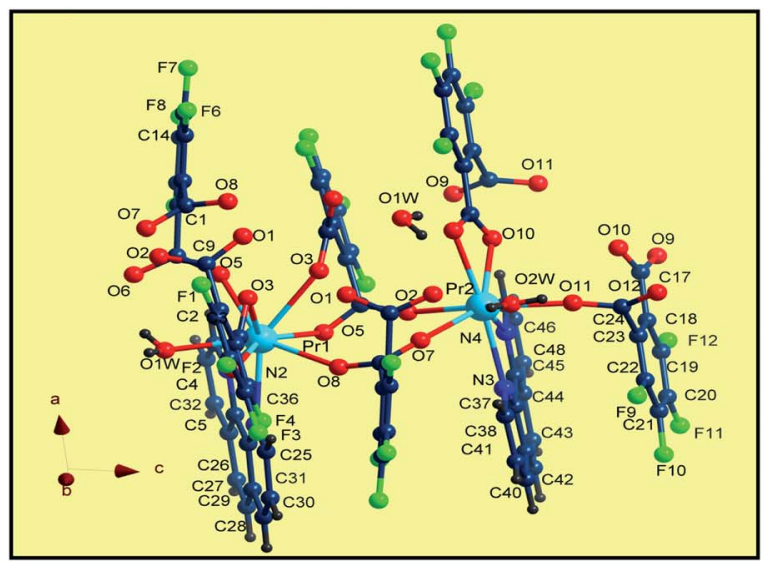

(a)

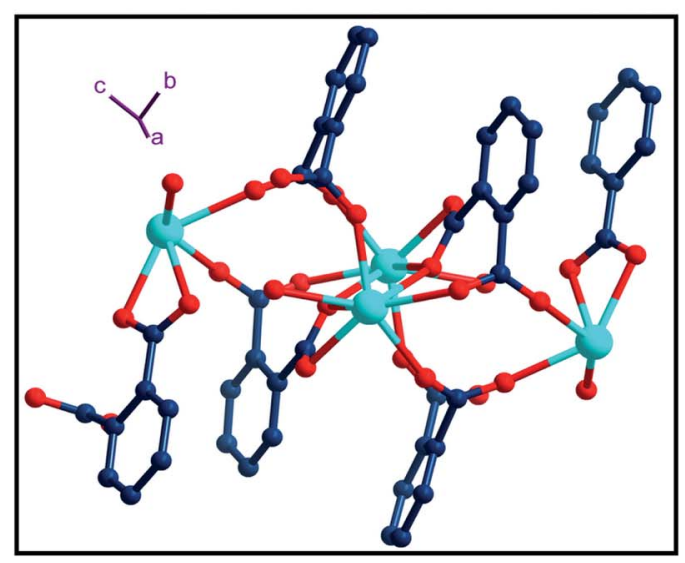

(b)

Fig. 1 (a) The coordination environments of $\operatorname{Pr}($ III) ions in the asymmetric unit in 1. (b) Diamond representation of tetranuclear clusters connected by carboxylic groups.

a distorted square-antiprismatic geometry and is octacoordinated with an $\mathrm{O}_{6} \mathrm{~N}_{2}$ donor set, among which five $\mathrm{O}$ atoms are from $\mathrm{Tfbda}$, one $\mathrm{O}$ atom is from the water molecule, and two $\mathrm{N}$ atoms originate from the chelating Phen moiety. Bond distance of $\operatorname{Pr}(1)-\mathrm{N}$ is found to be about 2.564(11) $\AA$, and the $\mathrm{Pr}(\mathrm{III})-\mathrm{O}$ distances are in range of 2.341(10) to 2.623(12) $\AA$. Bond angles of $\mathrm{O}-\mathrm{Pr}(\mathrm{III})-\mathrm{O}$ are in range of $68.5(4)^{\circ}$ to $153.2(3)^{\circ}$. The Tfbda ligand exhibits both chelating and bridging modes to connect $\operatorname{Pr}($ III) ions, among which the first deprotonated carboxylic group adopt $\mu_{3}-k \mathrm{O}, \mathrm{O}^{\prime}: k \mathrm{O}^{\prime}, \mathrm{O}^{\prime \prime}: k \mathrm{O}^{\prime \prime \prime}$ fashion connecting three adjacent $\operatorname{Pr}(\mathrm{III})$ centers, as illustrated in Scheme 1(a). This ligating fashion is also observed in a reported analogous lanthanide coordination polymer. ${ }^{23}$ Both benzene and pyridine rings with appended chromophoric units contribute to coordination to tailor the local symmetry of the Ln(III) ion. It is remarkable that the deprotonated Tfbda anion employs a carboxylic group that doubly connects two adjacent $\operatorname{Pr}($ III) ions into a binuclear unit, $\left[\mathrm{Pr}_{2}(\mathrm{COO})_{2}\right]$ (Scheme $1(\mathrm{~d})$ ), with the shortest $\operatorname{Pr} \cdots \operatorname{Pr}$ distance of $4.560 \AA$. Meanwhile, carboxylic oxygen atoms from opposite directions connect these binuclear units into tetra-nuclear clusters, as displayed in Fig. 1(b). These

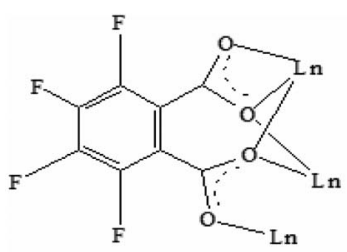

(a)<smiles>COC(=O)c1c(F)c(F)c(F)c(F)c1C(=O)O</smiles>

(c)<smiles>OC(O)c1c(F)c(F)c(F)c(F)c1C(O)O</smiles>

(b)

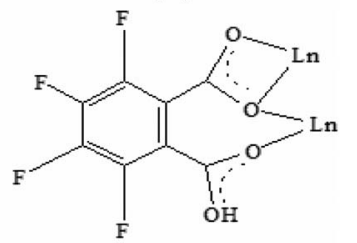

(d)
Scheme 1 Ligation models of Tfbda anion ligand in coordination polymers $1-6$. binuclear units are further extended into a one dimensional (1D) ribbon-double alternative chain through the carboxylic group from the phthalate moiety, as displayed in Fig. 2. The hydrogen bonds are originated from the carboxylic group of the phthalate moiety and stabilize these 1-D chains. Close inspection also finds the presence of strong hydrogen bonding interactions between adjacent carboxylic groups from the phthalate moiety and the coordinating water from the neighboring binuclear unit, such as $\mathrm{O}(1 \mathrm{w})-\mathrm{H}(1 \mathrm{w}) \cdots \mathrm{O}(9)$ and $\mathrm{O}(6)-\mathrm{H}(1 \mathrm{w}) \cdots$ $\mathrm{O}(1 \mathrm{w})$. These weak interactions further link 1-D chains to give rise to a 3D supramolecular architecture and contribute to stabilizing the crystal, ${ }^{24}$ as described in Fig. S2 and S3 in the ESI. $\dagger$ In the asymmetric unit of 3 , besides two kinds of octacoordinated Dy(III), there is also a low-symmetry nonacoordinated Dy(III) ion, exhibiting a distorted dodecahedron geometry, and four Tfbda ligands, one Tfbda ligand, one Phen ligand, as well three water molecules. Obviously, the Tfba moiety was in situ generated from the $\mathrm{H}_{2}$ Tfbda ligand. The Dy1, Dy2, and Dy3 ions present a trigonal planar geometry and are interconnected by two types of $\mathrm{COO}$ groups, forming a $\left[\mathrm{Dy}_{3}\right]$ unit. It further gives rise to infinite 1D zigzag chain structures constructed from the trinuclear clusters, as illustrated in Fig. S4 (ESI†). In contrast to the other coordination polymers, 2 is just a zero-dimensional compound; its detailed structure is illustrated in Fig. S5 and S6 (ESI†).

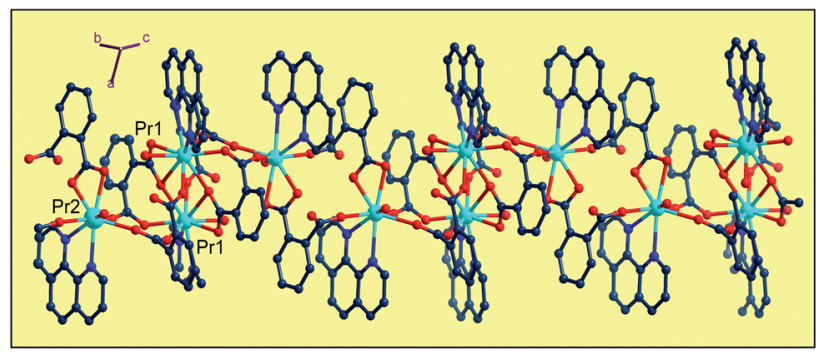

Fig. 2 Diamond illustration of propagating the binuclear $\left[\operatorname{Pr}_{2}(\mathrm{Tfbda})_{2}\right]$ units into a 1D alternate chain array constructed from alternate binuclear clusters. 


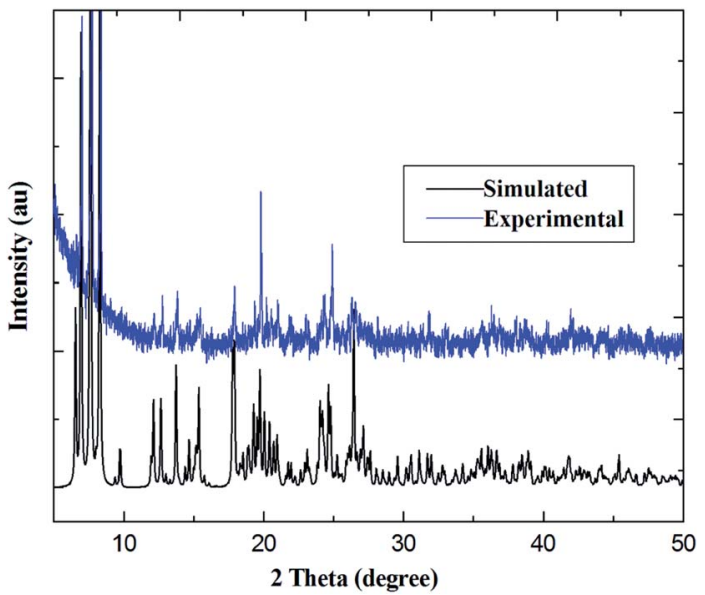

Fig. 3 Comparison of simulated and experimental PXRD patterns for $\operatorname{Pr}(I I I)$ compound 1.

\section{Thermal gravimetric analysis and PXRD pattern}

PXRD patterns for coordination polymers 1-6 are reported in Fig. 3 and S7-S12 (ESI $\dagger$ ). As illustrated in Fig. 3, for coordination polymer $\mathbf{1}$, both the simulated diffraction patterns and those from bulk powders demonstrate eight sharp and broad peaks at $2 \theta$ about $6.7^{\circ}, 7.5,13.6^{\circ}, 17.4^{\circ}, 18.7^{\circ}, 22.2^{\circ}, 25.9^{\circ}$ and $26.9^{\circ}$, respectively. Comparison of the experimental PXRD pattern of the bulk synthesized sample $\mathbf{1}$ with those simulated from its single crystal structure finds peak positions of the experimental patterns are nearly matched to those of the corresponding simulations generated from single-crystal X-ray diffraction data, which confirms that the bulk materials have the same pure phrase as the single crystals.

In order to verify the presence of water molecules in the series of coordination polymers, and to confirm the polymers' thermal stability, the series of coordination polymers are further investigated by thermogravimetric/differential thermal analysis (TG-DTA) under $\mathrm{N}_{2}$ atmosphere. As indicated in Fig. 4, all coordination polymers display nearly similar thermal behaviors; therefore, compound $\mathbf{1}$ is described as present here. The TG curve displays an initial weight loss of $4.96 \%$ (calculated: $5.01 \%$ ) in the temperature range of $120-160{ }^{\circ} \mathrm{C}$, and showing a gradually exothermic process in the DTA diagram. This corresponds to the release of two lattice and two coordination water molecules. In the second period, the weight loss is approximately $24.92 \%$ (calculated: $25.24 \%$ ) in range of $330-$ $370{ }^{\circ} \mathrm{C}$, with an obvious exothermic process. This corresponds to the removal of two Phen moieties. Beyond these temperatures, the coordination polymers begin to decompose, resulting in a concomitant elimination of three $\mathrm{H}_{2} \mathrm{Tfba}$ ligands. No plateau was observed until $990{ }^{\circ} \mathrm{C}$, indicating a relatively high thermal stability of the coordination polymers 1-6.

\section{Photoluminescence properties}

Recent years have witnessed the great effort focused on the Ln(III) metal-organic frameworks with light-harvesting building blocks, especially NIR emission with high-quality yield. ${ }^{25}$ These frameworks have attracted considerable attention over the last
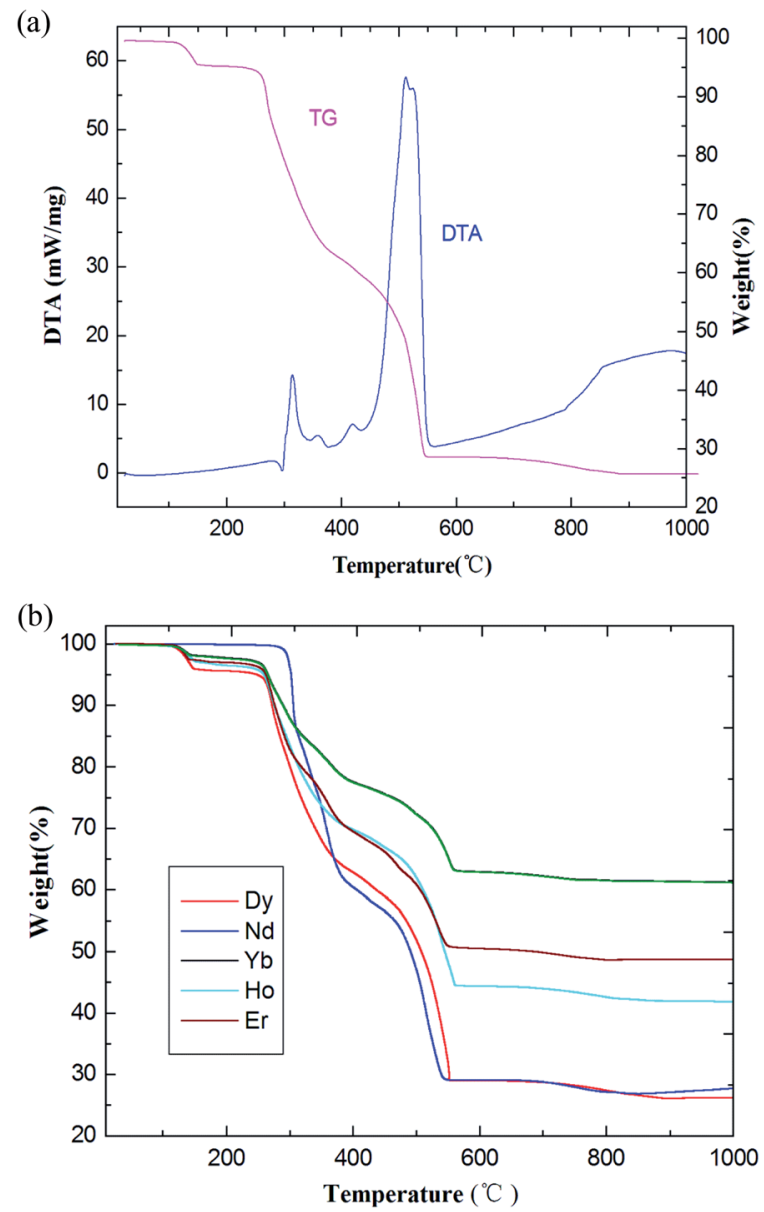

Fig. 4 (a) The TG-DTA diagrams of coordination polymer 1. (b) TG curves of coordination polymers $2-6$.

decades due to a wide array of potential applications, providing an excellent platform to study the excitation transport within frameworks. ${ }^{20}$ For the sake of comparison, the solid-state fluorescence behaviors of free $\mathrm{H}_{2}$ Tfbda and Phen ligands and the series of coordination polymers were recorded at room temperature on crushed crystal samples (Fig. S13 and S14, ESI $\dagger$ ). The combined excitation-emission spectra for compounds 1-6 are given in Fig. 5-10. On the basis of the calculation (see ESI $\dagger$ ) by determining the phosphorescence of Gd(III) compound 7 (Fig. S14, ESI $\dagger$ ), the mixed ligands have the triplet excited state energy of about $22460 \mathrm{~cm}^{-1}$, which is much higher than the lot of energy levels of $\operatorname{Ln}($ III), showing the occurrence of efficient energy transfer from the ligand to the lanthanide center. ${ }^{26}$ As shown in Fig. 5, upon excitation of $376 \mathrm{~nm}$ for the coordination polymer 1 , weak characteristic NIR luminescence of the $\operatorname{Pr}(\mathrm{III})$ ion was obtained (Fig. 5(a)). Assuming a common excited state originated from the absorption spectrum of the $\mathrm{H}_{2}$ Tfbda ligand (355 nm), NIR emission from the $\operatorname{Pr}($ III) coordination polymer with a maximum at $1026 \mathrm{~nm}$ was observed, which can then be assigned to the ${ }^{1} \mathrm{D}_{2}$ $\rightarrow{ }^{3} \mathrm{~F}_{4}$ transition; this is similar to previously reported $\operatorname{Pr}(\mathrm{III})$ compounds. ${ }^{27,28}$ Fig. 5(b) depicts a detailed scheme of the energy transfer process of the $\operatorname{Pr}(\mathrm{III})$ : firstly, the mixed ligands 


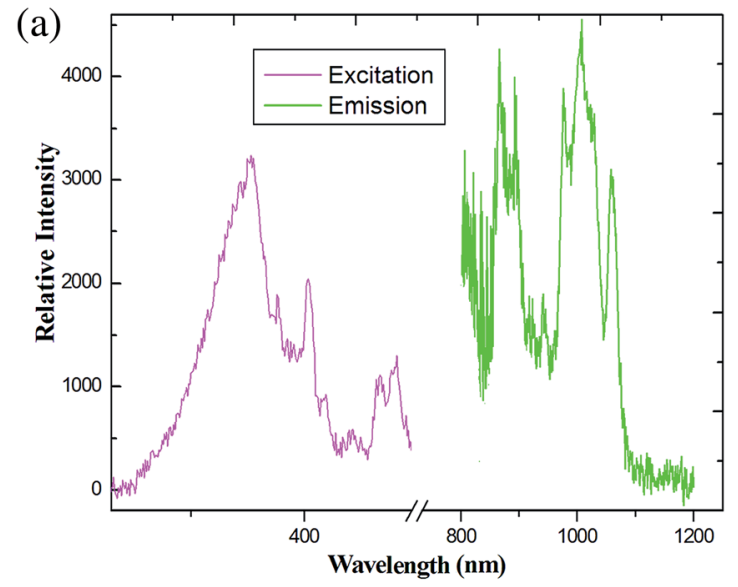

(b)

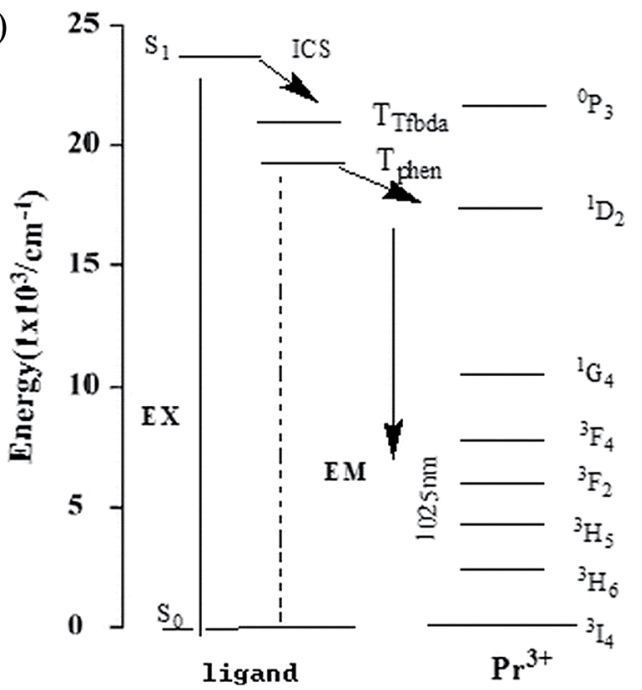

Fig. 5 (a) The excitation (monitored at $\lambda_{\mathrm{em}}=980 \mathrm{~nm}$ ) and emission spectra $\left(\lambda_{\text {ex }}=376 \mathrm{~nm}\right.$ ) of coordination polymer 1 in solid state. (b) Energy level scheme showing energy transfer processes in 1.

absorb energy and transfer it to $4 \mathrm{f}$ levels of the $\operatorname{Pr}(\mathrm{III})$ ions through an intramolecular process. Then, a relaxation to ${ }^{1} \mathrm{D}_{2}$ level occurs, followed by decay to ${ }^{2} \mathrm{~F}_{3},{ }^{3} \mathrm{H}_{4},{ }^{3} \mathrm{H}_{5}$ and ${ }^{3} \mathrm{H}_{6}$ states, respectively. The moderate luminescence is due to the triplet state of the ligand inexactly matching the excited emission state of $\operatorname{Pr}(\mathrm{III})$.

Studies with examples of sensitized photoluminescence of $\operatorname{Pr}($ III) complexes are relatively rare and are usually confined to the analysis of steady-state emission spectra. ${ }^{29}$ Luminescence intensity and lifetime resolution is very difficult to measure. The reason for the poor signal of the carboxylate linker can probably be found in the fact that its triplet level is most likely too high (larger energy gap) for efficient energy transfer to the emissive states of the $\operatorname{Pr}\left(\right.$ III) ions. ${ }^{30}$ The time-resolved phosphorescence decay profiles of the coordination polymer were measured in order to further investigate the luminescent features for the series of compounds. Time-resolved phosphorescence decay profiles were recorded on the FLS1000 instrument in powder state at $298 \mathrm{~K}$ (Fig. S15-S20, ESI $\dagger$ ), and luminescent quantum efficiencies $(q)$ were also measured on a Hamamatsu C11347-12
QY spectrometer. Luminescence lifetime measurements on the transition of ${ }^{1} \mathrm{D}_{2} \rightarrow{ }^{3} \mathrm{~F}_{4}(1025 \mathrm{~nm})$ for 1 gave biexponential decay kinetics in the range of $\tau_{1}=872.71 \mathrm{~ns}$ to $\tau_{2}=28617.18 \mathrm{~ns}$ (Fig. S15, ESI $\dagger$ ). The excited-state lifetime and quantum yields for compounds 1-6 are listed in Table 2. An estimated quantum yield of 2 may be calculated by comparing the luminescence lifetime of 2 with the natural lifetime of $\mathrm{Nd}$ (III). By using $\Phi=\tau$ / $\tau_{0}$, a value of $4.47 \%$ for 2 is calculated, given a value $\tau_{0}$ for the natural lifetime of $\mathrm{Nd}(\mathrm{III})=270 \mu \mathrm{s}$. The quantum yield of the $\mathrm{Yb}(\mathrm{III})$ coordination polymer luminescence was determined by taking $\left[\mathrm{Yb}(\mathrm{tta})_{3} \mathrm{Phen}\right]$ (tta $=$ thenoyl trifluoroacetonate) as a standard. ${ }^{31}$

As shown in Fig. 6, upon excitation of the coordination polymer, an absorption band at $403 \mathrm{~nm}$, which is the characteristic NIR luminescence of the $\mathrm{Nd}(\mathrm{III})$ ion, was obtained for 2 (see Fig. 6(a)). The emission spectra consist of three bands around 885, 1064 and $1341 \mathrm{~nm}$, corresponding to the transitions of ${ }^{4} \mathrm{~F}_{3 / 2} \rightarrow{ }^{4} \mathrm{I}_{9 / 2},{ }^{4} \mathrm{~F}_{3 / 2} \rightarrow{ }^{4} \mathrm{I}_{11 / 2}$ and ${ }^{4} \mathrm{~F}_{3 / 2} \rightarrow{ }^{4} \mathrm{I}_{13 / 2}$, respectively. The strongest emission is observed around $1065 \mathrm{~nm}$, which is the dominant NIR emission. Relative intensity of the $\mathrm{Nd}$ (III) luminescence for coordination polymer 2 is in agreement with the previously reported spectra of other Nd(III) complexes. ${ }^{32}$ The strongest emission around $1060 \mathrm{~nm}$ is potentially applied to the infrared laser emitter optical amplifier system, while the

Table 2 Luminescence decay time, maximum emission and quantum yields for compounds 1-6

\begin{tabular}{lccl}
\hline $\begin{array}{l}\text { Coordination } \\
\text { polymers }\end{array}$ & $\begin{array}{l}\lambda_{\text {em }} \\
\max (\mathrm{nm})\end{array}$ & ${\text { Lifetime }(\mu \mathrm{s})^{a},\left(\chi^{2}\right)} \begin{array}{l}\text { Quantum yields } \\
(\%)\end{array}$ \\
\hline $\operatorname{Pr}(\mathbf{1})$ & 1026 & $5.23(1.07)$ & 1.27 \\
$\mathrm{Nd}(2)$ & 1063 & $20.33(1.13)$ & 3.27 \\
Dy (3) & 576 & $24.7(1.23)$ & 7.82 \\
Ho (4) & 982 & $5.45(1.15)$ & 0.83 \\
Er $(5)$ & 1543 & $7.95(1.08)$ & 1.62 \\
Yb $(6)$ & 985 & $22.68(1.21)$ & 3.18
\end{tabular}

${ }^{a}$ The reduced chi-square is defined as: $\chi^{2}=\sum W_{\mathrm{k}}{ }^{2} \frac{\left[x_{\mathrm{k}}-F_{\mathrm{k}}\right]^{2}}{n}$.

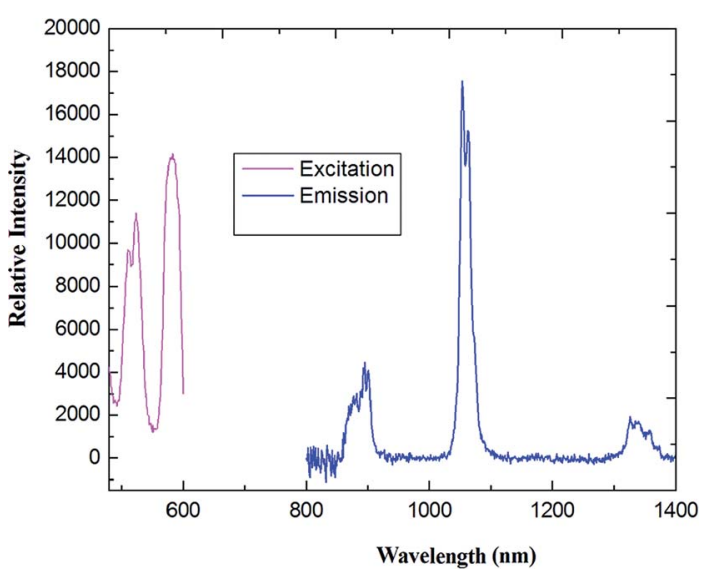

Fig. 6 The excitation (monitored at $\lambda_{\mathrm{em}}=1100 \mathrm{~nm}$ ) and emission spectra $\left(\lambda_{\text {ex }}=456 \mathrm{~nm}\right)$ of coordination polymer $2(\mathrm{Nd})$ in solid state. 
emission band maximum at $1340 \mathrm{~nm}$ offers the opportunity to develop new materials suitable for optical amplifiers operating at $1.3 \mu \mathrm{m}$. Assuming the energy is firstly transferred to $4 \mathrm{f}$ levels of the $\mathrm{Nd}(\mathrm{III})$ ion through an intramolecular process, then a relaxation to ${ }^{4} \mathrm{~F}_{3 / 2}$ level happens, ${ }^{33}$ followed by decay to ${ }^{4} \mathrm{I}_{9 / 2}$, ${ }^{4} \mathrm{I}_{11 / 2}$ and ${ }^{4} \mathrm{I}_{13 / 2}$ states, respectively.

The solid-state photoluminescence spectra of 3 were measured under excitation at $342 \mathrm{~nm}$, as reported in Fig. 7. The compound shows the typical multiband emission of Dy(III), and luminescence peaks occur at 486 and $576 \mathrm{~nm}$, assigned to the transitions of ${ }^{4} \mathrm{~F}_{9 / 2} \rightarrow{ }^{6} \mathrm{H}_{15 / 2}$ and ${ }^{4} \mathrm{~F}_{9 / 2} \rightarrow{ }^{6} \mathrm{H}_{13 / 2}$, respectively. The high-intensity sensitive peak at ${ }^{4} \mathrm{~F}_{9 / 2} \rightarrow{ }^{6} \mathrm{H}_{13 / 2}$ is assigned to the signature transition of Dy(III), ion which imparts yellow color in the emission. ${ }^{34,35}$ The transition ${ }^{4} \mathrm{~F}_{9 / 2} \rightarrow{ }^{6} \mathrm{H}_{15 / 2}$ is magnetically allowed and does not change with a change in the local field around the Dy(III) ion. The more intense ${ }^{4} \mathrm{~F}_{9 / 2} \rightarrow{ }^{6} \mathrm{H}_{13 / 2}$ is a forced electric-dipole transition and is prominent only when the Dy(III) ion is located at a low-symmetry site..$^{36} \mathrm{~A}$ strong protective shield is provided by the coordination of low frequency $\mathrm{C}-\mathrm{F}$ vibrational oscillators, and the rigid ancillary Phen ligand around the central ion ascribes higher quantum yields and longer radioactive lifetimes to the $\mathrm{Nd}$ (III) compound. Moreover, there is an efficient ligand-to-metal energy transfer process in this complex, as proved by the absence of emission of the ligand. ${ }^{37}$ The values of the observed decay times can be compared with values obtained for other lanthanide complexes, ${ }^{38}$ which are much longer than those reported for Nd-quinolinate complexes, in the order of 0.5 $\mu \mathrm{s}^{39}$ The quantum efficiency $(q)$ of 2 is comparable to the results from azulene-moiety-based $\mathrm{Nd}(\mathrm{III})$ compounds. $^{40}$ The photoluminescence (PL) intensity is relatively strong, indicating its potential application for quantitative analysis. From Table 2, as a crude approximation, one can state that the longer the observed luminescence decay time, the more efficient the luminescent material is. ${ }^{41}$

As indicated in Fig. 8, the steady-state emission spectra of coordination polymer 4 was obtained by fixing $312 \mathrm{~nm}$ as the excitation wavelength. The maximum of the weak emission band is located at about $990 \mathrm{~nm}$, corresponding to the ${ }^{5} \mathrm{~F}_{5} \rightarrow{ }^{5} \mathrm{I}_{7}$ transition of the holmium ion.

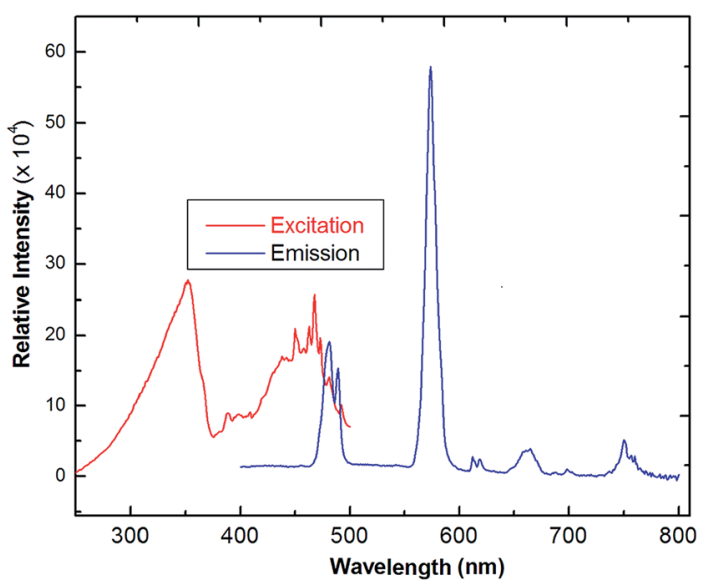

Fig. 7 The excitation and solid-state emission spectra of Dy(III) coordination polymer (3) ( $\left.\lambda_{\mathrm{ex}}=342 \mathrm{~nm}\right)$.

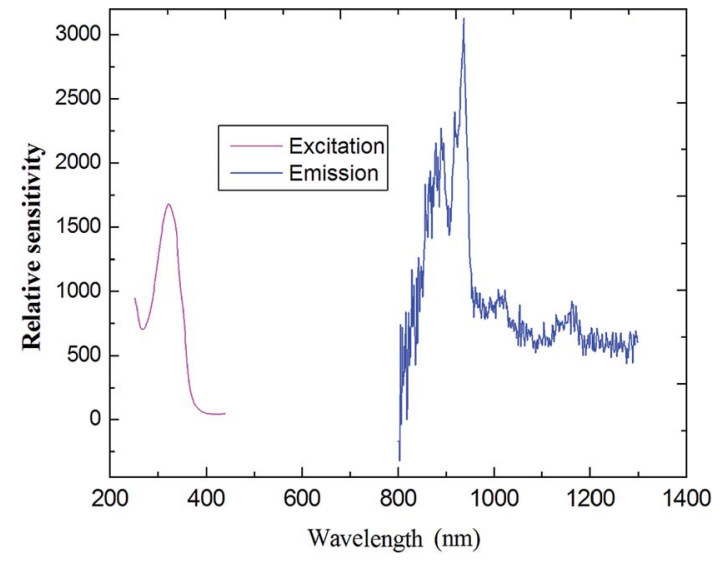

Fig. 8 The excitation (monitored at $\lambda_{\mathrm{em}}=808 \mathrm{~nm}$ ) and emission spectra of compound $4(\mathrm{Ho})$ as solid state.

Upon excitation maximum at $356 \mathrm{~nm}$, characteristic NIR luminescence of the $\operatorname{Er}(\mathrm{III})$ ion was obtained for 5 (Fig. 9); the emission bands cover the spectral range extending from 1480 to $1630 \mathrm{~nm}$, with the emission peak at $1537 \mathrm{~nm}$. The obtained emissions are attributed to the typical ${ }^{4} \mathrm{I}_{13 / 2} \rightarrow{ }^{4} \mathrm{I}_{15 / 2}$ transition of $\operatorname{Er}($ III) ion. The $\operatorname{Er}($ III)-based complexes are particularly interesting for application in amplification, since the transition around $1540 \mathrm{~nm}$ is in the right position for the third telecommunication window. ${ }^{41}$ The full width at half maximum of the ${ }^{4} \mathrm{I}_{13 / 2} \rightarrow{ }^{4} \mathrm{I}_{15 / 2}$ transition for compound 5 is $82 \mathrm{~nm}$, which enables a wide-gain bandwidth for optical amplification. ${ }^{42}$ The profiles of the emission bands and the relative intensity of luminescence for the $\operatorname{Er}(\mathrm{III})$ coordination polymer are different from the previously reported spectra of Er(III) complexes, ${ }^{43}$ in which just single emission band is present, which indicates ligands may have some influence (including red shift) on the luminescence intensity of the compound. ${ }^{44}$

Upon excitation at $394 \mathrm{~nm}$, the emission spectra of compound 6 shows the characteristic emission bands for the $\mathrm{Yb}$ (III) ion (which has a maximum at $985 \mathrm{~nm}$ ), which are assigned to the ${ }^{2} \mathrm{~F}_{5 / 2} \rightarrow{ }^{2} \mathrm{~F}_{7 / 2}$ transition (Fig. 10). It is clearly observed that the emission is not a single sharp peak but, rather, appears as two broad bands centered at 968 and $1032 \mathrm{~nm}$. A similar splitting had been previously reported and is attributed to the $M_{\mathrm{J}}$ splitting of the emission or stark splitting arising at fundamental and higher state energies, ${ }^{45}$ as a consequence of ligand field effects. ${ }^{46}$ This phenomenon is also found in the previously reported $\mathrm{Yb}(\mathrm{III})$ compound. ${ }^{47}$ It important in laser emission for $\mathrm{Yb}(\mathrm{III})$ compound due to the simple $\mathrm{f}-\mathrm{f}$ energy level structure, and there is no excited-state absorption reducing the effective laser cross-section, no up-conversion, no concentration quenching and no absorption in the visible region. ${ }^{48}$

There is no emission in the spectra based on ligands, which is attributed to efficient energy transfer from the ligands to the central $\operatorname{Ln}(\mathrm{III})$ ion, i.e., an antenna effect. With these NIRluminescent lanthanide complexes above, the luminescent spectral region is from 1200 to $1600 \mathrm{~nm}$, which is of particular importance for telecommunication applications. Mixed rigid 
(a)

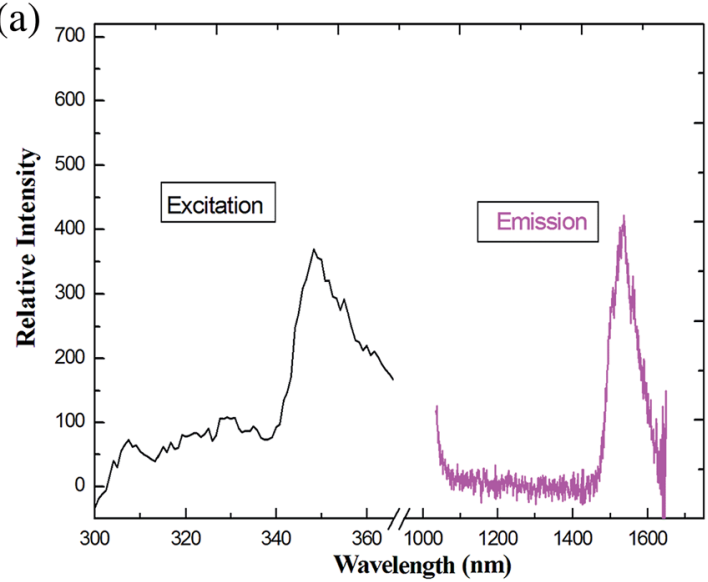

(b)

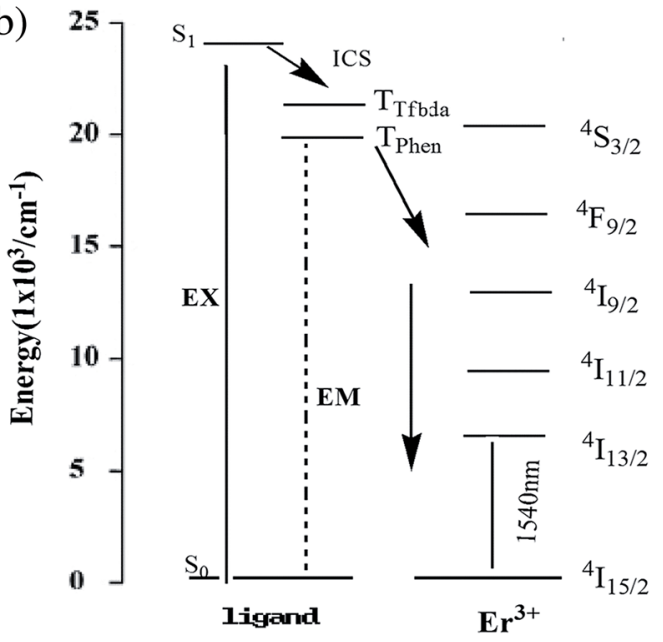

Fig. 9 (a) The excitation (monitored at $\lambda_{\mathrm{em}}=660 \mathrm{~nm}$ ) and emission spectra $\left(\lambda_{\text {ex }}=376 \mathrm{~nm}\right.$ ) of 5 in solid state. (b) Energy level scheme showing energy transfer processes in 5 .

fluorophores serve as efficient organic antenna sensitizers for luminescence from a wide variety of lanthanides (with the possible exception of $\operatorname{Pr}(\mathrm{III})$ and $\mathrm{Ho}(\mathrm{III})$ compounds). The discrepancy of photoluminescence properties is due to the energy gap between the excited triplet state (levels) of the ligand

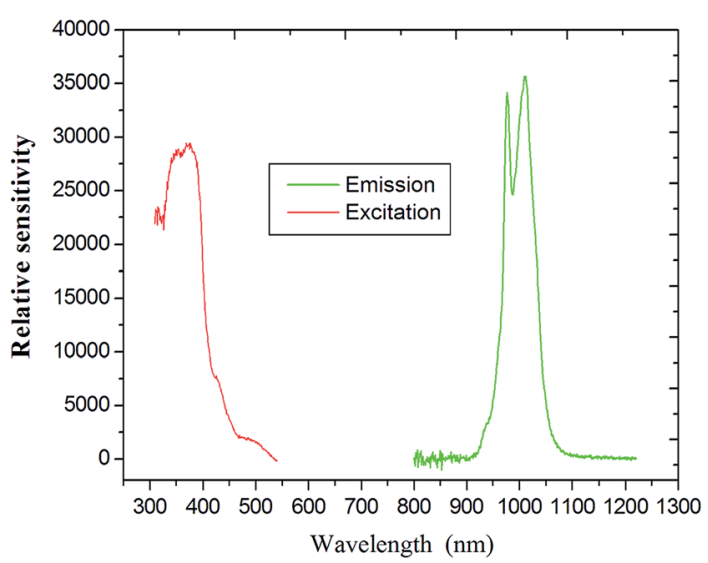

Fig. 10 Emission spectra and illustration of the ${ }^{5} \mathrm{D}_{0} \rightarrow{ }^{7} \mathrm{~F}_{2}$ transition intensities of coordination polymer Yb (excited at $394 \mathrm{~nm}$ ). and the emitting, excited state of $\operatorname{Ln}(\mathrm{III})$ ions introduced in the coordination polymers.

\section{Magnetic properties}

The direct current (DC) magnetic susceptibility of coordination polymer 3 is measured on crushed crystals under an applied 1 kOe from 300 to $2.0 \mathrm{~K}$ temperature range. The plots of $\chi_{\mathrm{M}} T$ and $\chi_{\mathrm{M}}$ versus $T$ are reported in Fig. 11. From these, we can see the $\chi_{\mathrm{M}} T$ value of compound 3 at $300 \mathrm{~K}$ is $43.22 \mathrm{~cm}^{3} \mathrm{~K} \mathrm{~mol}^{-1}$, which is close to the expected value $\left(42.51 \mathrm{~cm}^{3} \mathrm{~K} \mathrm{~mol}^{-1}\right)$ for three noninteracting Dy(III) ions $\left({ }^{6} \mathrm{H}_{15 / 2}, S=5 / 2, L=5, J=15 / 2, g=4 /\right.$ $3)$. As the temperature is lowered, initially, the $\chi_{\mathrm{M}} T$ products for 3 exhibit a monotonic slow decrease until it reaches minimum value $\left(36.06 \mathrm{~cm}^{3} \mathrm{~K} \mathrm{~mol}^{-1}\right)$ at $9 \mathrm{~K}$, which indicates the thermal behaviors could arise from the thermal depopulation of the Dy(III) Stark sublevels or weak antiferromagnetic (AF) interaction dominating the Dy(III) coordination polymer at higher temperature. Upon further lowering of the temperature, $\chi_{\mathrm{M}} T$ increases abruptly and finally rapidly reaches a value of 44.18 $\mathrm{cm}^{3} \mathrm{~K} \mathrm{~mol}^{-1}$ at $2 \mathrm{~K}$, indicating a ferromagnetic-like behavior or a system of spin canting, followed by the effect of the D parameter (or saturation phenomena).

The field dependence of the magnetization of 3 was measured at the temperatures of 2,3 , and $5 \mathrm{~K}$; the magnetization of 3 increases with a relatively rapid speed under weak fields (Fig. S21, ESI $\dagger$ ). The expected saturation value of $30 \mu \beta$ is not achieved..$^{49}$ The $M$ versus $H$ plots do not superimpose in a master curve, even at high magnetic fields. The lack of saturation on the $M$ versus $H$ data even at $2 \mathrm{~K}$ may be explained by the presence of a significant magnetic anisotropy and/or lowlying excited states. ${ }^{50}$ Because of the magnetic anisotropy for this compound, magnetization dynamics are expected for $\mathbf{3}$, which is one of the most important characteristics of SMMs measured under alternating-current (AC) magnetic field with varied frequencies and temperatures. ${ }^{51}$

The AC susceptibility was measured under a zero directcurrent (DC) field, $H_{\mathrm{ac}}=3$ Oe, with different frequencies to probe the dynamic magnetic behaviors. The out-of-phase

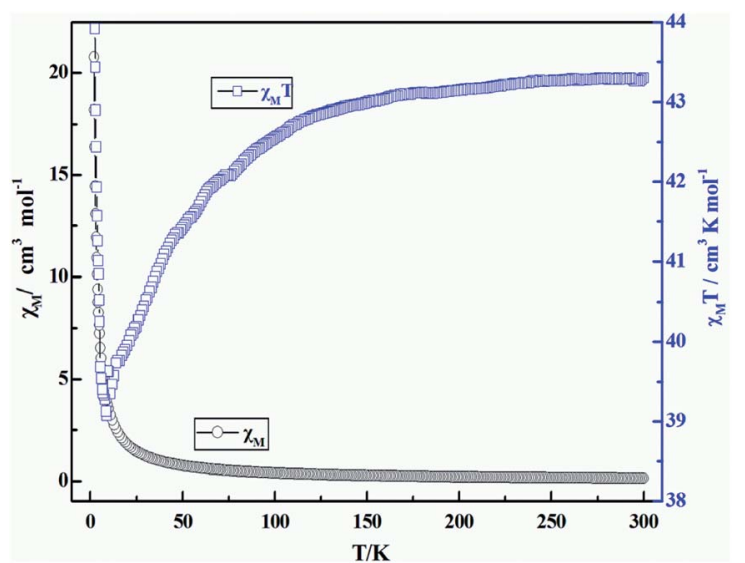

Fig. 11 Temperature dependence of $\chi_{M} T(\square)$ and $\chi_{M}(O)$ versus $T$ for coordination polymer 3 under the magnetic field of $1000 \mathrm{Oe}$. 
susceptibility shows obvious frequency-dependent signals, but some of maxima peaks for $\chi^{\prime}$ are not found under zero DC field, which is mainly due to the fast quantum tunneling of the magnetization (QTM). ${ }^{52}$ External DC fields ranging in value from 250 to 2500 Oe were further tested in order to identify the magnetic field value that optimally suppresses QTM. The optimized value, a 300 Oe DC field, was applied to measure the AC magnetic susceptibility. The measurements were performed under a frequency of $10-1000 \mathrm{~Hz}$ as a way to study the magnetization dynamics of 3. Both in-phase $\left(\chi^{\prime}\right)$ and out-of-phase $\left(\chi^{\prime \prime}\right)$ AC signals show strong frequency dependence, indicating magnetization dynamics in compound 3 (see Fig. 12). $\chi^{\prime}$ and $\chi^{\prime \prime}$ were observed to increase as the temperature was cooled down to $2 \mathrm{~K}$, which suggests a slow relaxation process characteristic. ${ }^{52}$ Both temperature and frequency dependencies of the $\mathrm{AC}$ susceptibility were carried out, and well-resolved peaks emerged for the out-of-phase signals at high frequencies.

The magnetic behaviors are quite field-dependent; i.e., the increases of the $\chi^{\prime \prime}$ values at low temperature become less pronounced at higher fields. Upon increasing temperature under the DC field of 500 Oe, the coordination polymer 3 displays $\chi^{\prime \prime}$ peak positions shifting to lower frequencies. Assuming there is only one characteristic relaxation process of
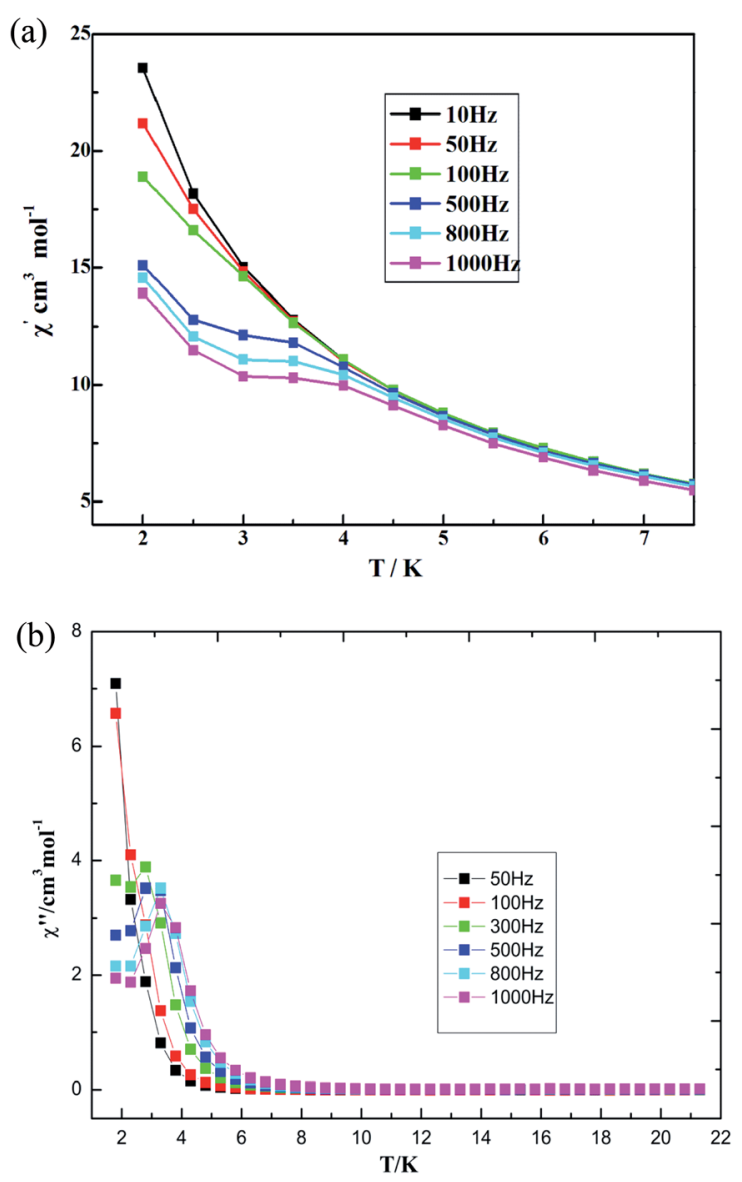

Fig. 12 Temperature dependence of (a) in-phase AC susceptibility and (b) out-of-phase AC susceptibility at various frequencies for 3 under a 300 Oe DC field. the Debye type with one energy barrier and one time constant, it can be used to evaluate (Orbach fitting) roughly the energy barrier and $t_{0}$ based on the following relationship, according to eqn (1) (see Fig. S22, ESI $\dagger$ ).

$$
\ln \left(\chi^{\prime \prime} / \chi^{\prime}\right)=\ln \left(w \tau_{0}\right)+E_{\mathrm{a}} / k_{\mathrm{B}} T
$$

Eqn (1) gives the results of $\Delta=12.8 \mathrm{~K}$ and $\tau_{0}=5.17(2) \times$ $10^{-6} \mathrm{~s}$, which is compareable with those obtained using the Arrhenius plot. The temperature dependence of the relaxation time at 300 Oe is extracted from the extended Debye model between 2.2 and $5.8 \mathrm{~K}$. The relaxation time follows the Arrhenius law only above $2.2 \mathrm{~K}$ (Fig. 13). The effective energy barrier $\left(U_{\text {eff }}\right)$ is obtained by Arrhenius law $\left(\tau=\exp \left(U_{\text {eff }} / k_{\mathrm{B}} T\right)\right)$, and fitting can be used to give a $U_{\text {eff }}$ of $\Delta=15.6 \pm 0.4 \mathrm{~K}$ with a preexponential factor $\tau_{0}$ of $7.61(3) \times 10^{-6} \mathrm{~s}$. These values are well within the range for SMMs. This finding suggests the presence of slow magnetic relaxation at a low temperature and, consequently, temperature field-induced SMM behaviors. ${ }^{53,54}$

On the basis of the frequency dependencies of the AC susceptibility measurements, Cole-Cole plots in the form of $\chi^{\prime \prime}$ versus $\chi^{\prime}$ with approximate semicircular shapes have been achieved (Fig. S23, ESI $\dagger$ ). The data have been fitted on the generalized Debye model, and the distribution coefficient $\alpha$ value (0.26, relatively little) has been in range 0.40-0.15 (between 2 and $4 \mathrm{~K}$ ). The Cole-Cole diagrams at 2 and $3 \mathrm{~K}$ exhibit obvious one-step thermal magnetic relaxation characteristic, corresponding to occurrence of the fast relaxation phase (FR). ${ }^{55}$

The temperature dependence of the $\chi_{M} T$ and $\chi_{M}$ for 7 is reported in Fig. 14. At room temperature, the product of $\chi_{\mathrm{M}} T$ is $c a$. $31.10 \mathrm{~cm}^{3} \mathrm{~mol}^{-1} \mathrm{~K}$, which is slightly less than the theoretical value of $31.52 \mathrm{~cm}^{3} \mathrm{~mol}^{-1} \mathrm{~K}$, the expected value for four uncoupled Gd(III) ions with $S=7 / 2, g=2.0$. Upon cooling, the $\chi_{\mathrm{M}} T$ product gradually increases up to the maximum of 34.18 $\mathrm{cm}^{3} \mathrm{~mol}^{-1} \mathrm{~K}$ at $2 \mathrm{~K}$. This behavior is indicative of the presence of possible weak ferromagnetic interactions between the adjacent Gd(III) ions. The $\mathrm{Gd}(\mathrm{III})$ ion has a ${ }^{8} \mathrm{~S}_{7 / 2}(L=0)$ ground state configuration, which is spherically symmetric and is therefore not susceptible to crystal field effect. ${ }^{56}$ The structure of compound 7 can be viewed as 1-D composed from tetranuclear

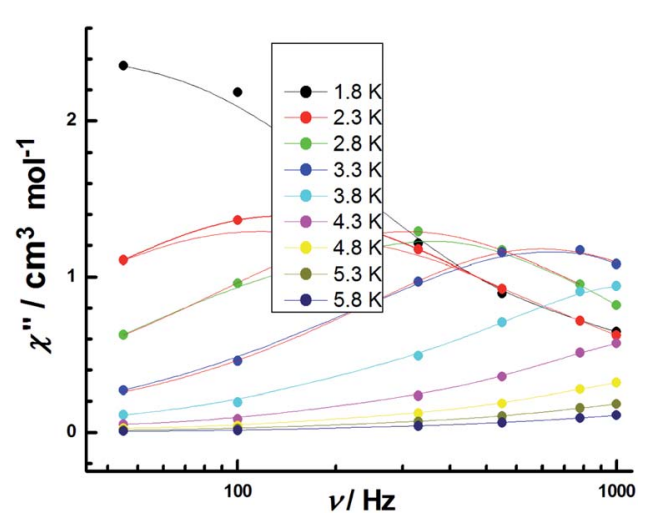

Fig. 13 Frequency dependence of the out-of-phase $\chi^{\prime \prime}$ products for 3 in temperature range of $1.8-5.8 \mathrm{~K}$ under an applied DC field of $300 \mathrm{Oe}$ with an oscillating field of $3 \mathrm{Oe}$. 


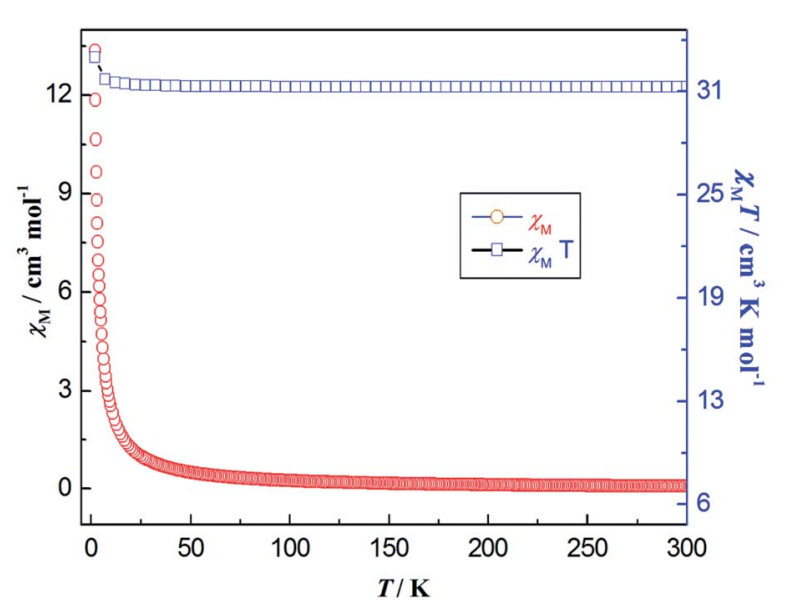

Fig. 14 Thermal variation (temperature dependence) of $\chi_{M} T(\square)$ and $\chi_{M}(O)$ versus $T$ for coordination polymer 7 under the DC magnetic field of 1000 Oe.

clusters, and there is no available expression to determine the accurate magnetic susceptibilities of such structure. ${ }^{57,58}$ Alternately, within the entire temperature range, the temperature dependence of the reciprocal magnetic susceptibilities $\left(1 / \chi_{M}\right)$ obeys the Curie-Weiss law $\left[\chi_{\mathrm{M}}=C /(T-\theta)\right]$. The best fit of the magnetic susceptibility of 7 in the whole temperature range gives the parameters $\theta=9.71 \mathrm{~K}, C=31.25 \mathrm{~cm}^{3} \mathrm{~K} \mathrm{~mol}^{-1}$, and $R=$ $3.15 \times 10^{-6}$. (See Fig. S24, ESI $\dagger$ ). The positive $\theta$ value $\chi_{\mathrm{M}} T$ decrease upon lowering the temperature may also support the weak ferromagnetic interaction dominating within the coordination polymer 7. The magnetic behavior in our case is similar to the reported azoxybenzene carboxylate-based lanthanide complex. $^{20}$

\section{Conclusions}

The family of lanthanide coordination polymers based on fluorine-substituted carboxylate and rigid Phen ligands have been designed and isolated successfully via economical synthetic procedures. Mixed rigid fluorophores, acting as an organic antenna, can efficiently sensitize a wide variety of lanthanides for luminescence emission. The coordination polymer 7 shows very weak ferromagnetic coupling between Gd-Gd centers. Importantly, coordination polymer 3 exhibits characteristic Dy(III) emission in the visible region with a long lifetime or high quantum yield; it also exhibits temperaturedependent and field-induced slow magnetic relaxation behaviors, and thus may serve as a candidate for a luminescent single molecular magnet. Therefore, this study will contribute to understanding the relationship between structures and properties, especially for spin-orbit couplings and the ligand field perturbation process.

\section{Conflicts of interest}

The authors declare no competing financial interest.

\section{Acknowledgements}

This work was supported by the Foundation for Science \& Technology Innovation Talents in Henan province (No. 164100510012), Natural Science Foundation of China (No. 21671114 and U1804113), and the Tackle Key Problem of Science and Technology Project of Henan Province, China (No. 182102310897).

\section{Notes and references}

1 X. Y. Wang, P. F. Yan, Y. X. Li, G. H. An, X. Yao and G. M. Li, Cryst. Growth Des., 2017, 17, 2178.

2 H. Y. Li, Y. L. Wei, X. Y. Dong, S. Q. Zang and T. C. W. Mak, Chem. Mater., 2015, 27, 1327.

3 G. R. Fu, J. Q. Guan, B. N. Li, L. Y. Liu, N. He, C. Yu, Z. Zhang and X. Q. Lu, J. Mater. Chem. C, 2018, 6, 4114.

4 Y. M. Feng, Q. B. Xiao, Y. H. Zhang, F. J. Li, Y. F. Li, C. Y. Li, Q. B. Wang, L. Y. Shi and H. Z. Lin, J. Mater. Chem. B, 2017, 5, 504.

5 Y. Y. Ning, J. Tang, Y. W. Liu, J. Jing, Y. S. Sun and J. L. Zhang, Chem. Sci., 2018, 9, 3742.

6 S. Y. Wu, Y. N. Lin, J. W. Liu, W. Shi, G. M. Yang and P. Cheng, Adv. Funct. Mater., 2018, 28, 1707169.

7 J. J. Li, T. T. Fan, X. L. Qu, H. L. Han and X. Li, Dalton Trans., 2016, 45, 2924.

8 S. Wang, L. Shan, Y. Fan, J. Jia, J. Xu and L. Wang, J. Solid State Chem., 2017, 245, 132.

9 Z. Y. Li, B. Zhai, S. Z. Li, G. X. Cao, F. Q. Zhang, X. F. Zhang, F. L. Zhang and C. Zhang, Cryst. Growth Des., 2016, 16, 4574.

10 S. J. Liu, J. P. Zhao, J. Tao, J. M. Jia, S. D. Han, Y. Li, Y. C. Chen and X. H. Bu, Inorg. Chem., 2013, 52, 916.

11 Y. Hasegawa, Y. Kitagawa and T. Nakanishi, NPG Asia Mater., 2018, 10, 52.

12 J. B. Yu, L. Zhou, H. J. Zhang, L. Y. X. Zheng, H. R. Li, R. P. Deng, Z. P. Peng and Z. F. Li, Inorg. Chem., 2005, 44, 1611.

13 J. N. Hao, X. Y. Xu, H. H. Fei, L. C. Li and B. Yan, Adv. Mater., 2018, 30, 1705634.

14 Z. Hulvey, E. Ayala, J. D. Furman, P. M. Forster and A. K. Cheetham, Cryst. Growth Des., 2009, 9, 4759.

15 X. Feng, Y. L. Sun and R. F. Li, Inorg. Chem. Commun., 2016, 73, 190.

16 B. Xu, Q. Chen, H. Hu, R. An, X. Wang and G. Xue, Cryst. Growth Des., 2015, 15, 2318.

17 X. Feng, Y. Q. Feng, N. Guo, Y. L. Sun, T. Zhang, L. F. Ma and L. Y. Wang, Inorg. Chem., 2017, 56, 1713.

18 G. M. Sheldrick, SHELXL-2014/7, Germany, 2014.

19 G. M. Sheldrick, SHELXL-2014/7, Germany, 2014.

20 X. Feng, N. Guo, H. P. Chen, H. L. Wang, X. X. Chen and L. Y. Yue, Dalton Trans., 2017, 46, 14192.

21 G. B. Deacon and R. J. Phillips, Coord. Chem. Rev., 1980, 33, 227.

22 X. Feng, X. L. Ling, L. Liu and L. Y. Wang, Dalton Trans., 2013, 42, 10292.

23 X. Feng, J. G. Wang, B. Liu, L. Y. Wang, J. S. Zhao and S. W. Ng, Cryst. Growth Des., 2012, 12, 927. 
24 F. N. Shi, L. C. Silva, T. Trindade, A. F. A. Paz, J. Rocha and J. Cryst, Cryst. Growth Des., 2009, 9, 2098.

25 J. G. A. Scholten, R. J. Wahsner, N. Alzakhem, C. Bischof and F. Stog, J. Am. Chem. Soc., 2012, 134, 1391.

26 J. C. G. Bunzli and C. Piguet, Chem. Soc. Rev., 2005, 34, 1048. 27 E. G. Moore, G. Szigethy, J. Xu, L. Plsson and A. Beeby, Angew. Chem. Int. Ed., 2008, 47, 9500.

28 G. M. Davies, R. J. Aarons, G. R. Motson, J. C. Jeffery, H. Adams, S. Faulkner and M. D. Ward, Dalton Trans., 2004, 1136.

29 A. I. Voloshin, N. M. Shavaleev and V. P. Kazakov, J. Lumin., 2001, 93, 199.

30 R. Decadt, K. V. Hecke, D. Depla, K. Leus, D. Weinberger and I. V. Driessche, Inorg. Chem., 2012, 51, 11623.

31 X. Yao, X. Wang, Y. G. Han, P. Yan, Y. Li and G. Li, RSC Adv., 2015, 5, 6585.

32 K. Lunstroot, P. Nockemann, K. V. Hecke, L. V. Meervelt, C. Görller-Walrand, K. Binnemans and K. Driesen, Chem, 2009, 48, 3018.

33 S. Chen, R. Q. Fan, C. F. Sun, P. Wang, Y. L. Yang, Q. Su and Y. Mu, Cryst. Growth Des., 2012, 12, 1337.

34 J. Feng and H. J. Zhang, Chem. Soc. Rev., 2013, 42, 387.

35 P. F. Shi, B. Zhao, G. Xiong, Y. L. Hou and P. Cheng, Chem. Commun., 2012, 48, 8231.

36 K. L. Hou, F. Y. Bai, Y. H. Xing, J. L. Wang and Z. Shi, CrystEngComm, 2011, 13, 3884.

37 Z. Ahmed and K. Iftikhar, J. Phys. Chem. A, 2013, 117, 11183. 38 Y. V. Korovin, N. V. Rusakova and Y. A. Popkov, J. Appl. Spectrosc., 2002, 69, 89.

39 R. Decadt, K. Van Hecke, D. Depla, K. Leus, D. Weinberger, I. Van Driessche, P. Van Der Voort and R. Van Deun, Inorg. Chem., 2012, 51, 1162.

40 R. Van Deun, P. Fias, P. Nockemann, K. Van Hecke, L. Van Meervelt and K. Binnemans, Eur. J. Inorg. Chem., 2007, 2, 302.

41 J. Zhang and S. Petoud, Chem.-Eur. J., 2009, 14, 1264.
42 Y. J. Cui, Y. F. Yue, G. D. Qian and B. L. Chen, Chem. Rev., 2012, 112, 1126.

43 L. N. Sun, H. J. Zhang, L. S. Fu, F. Y. Liu, Q. G. Meng, C. Y. Peng and J. B. Yu, Adv. Funct. Mater., 2005, 15, 1041.

44 L. N. Sun, J. B. Yu, G. L. Zheng, H. J. Zhang, Q. G. Meng, C. Y. Peng, L. S. Fu, F. Y. Liu and Y. N. Yu, Eur. J. Inorg. Chem., 2006, 19, 3962.

45 N. N. Sun and B. Yan, J. Alloy. Comp., 2018, 765, 63.

46 P. Lenaerts, K. Driesen, R. VanDeun and K. Binnemans, Chem. Mater., 2005, 17, 2148.

47 S. Comby, D. Imbert, C. Vandevyver and J. C. G. Bünzli, Chem. - Eur. J., 2007, 13, 936.

48 P. Lenaerts, K. Driesen, R. VanDeun and K. Binnemans, Chem. Mater., 2005, 17, 2148.

49 T. Zhang, X. Zhu, K. W. Wong, L. H. Tam and Y. W. Wong, Chem.-Eur. J., 2013, 19, 739.

50 S. Zhang, H. Ke, L. Sun, X. Li, Q. Shi, G. Xie, Q. Wei, D. Yang, W. Wang and P. S. Chen, Inorg. Chem., 2016, 55, 3865.

51 D. J. Rinehart, M. Fang, J. W. Evans and R. J. Long, J. Am. Chem. Soc., 2011, 133, 14236.

52 O. Kahn, Molecular Magnetism, VCH, Weinhem, Germany, 1993.

53 X. Y. Wang, Y. Ma, Y. Chai, W. Shi, Y. Sun and P. Cheng, J. Am. Chem. Soc., 2018, 140, 7795.

54 D. Gatteschi and R. Sessoli, Angew. Chem. Int. Ed., 2003, 42, 268.

55 T. Han, W. Shi, Z. Niu, B. Na and P. Cheng, Chem.-Eur. J., 2013, 19, 994.

56 Y. M. Li, B. Liu, W. B. Wang, M. Z. Wang, S. Gao and M. Kurmoo, Dalton Trans., 2011, 40, 6038.

57 X. Feng, S. J. Zhao, B. Liu, Y. L. Wang, G. J. Wang, S. N. Weng, G. Zhang, G. X. Shi and Y. Y. Liu, Cryst. Growth Des., 2010, 10, 1399.

58 L. Cañadillas-Delgado, O. Fabelo, J. Cano, J. Pasán, S. F. Delgado, F. Lloret, M. Julve and C. Ruiz-Pérez, CrystEngComm, 2009, 11, 2131. 